\title{
Um estudo sobre o conceito de empreendedor de políticas públicas: Ideias, Interesses e Mudanças
}

\author{
ANA CLÁUdia Niedhardt CAPELla \\ Universidade Estadual Paulista / Faculdade de Ciências e Letras, Departamento de Administração Pública, \\ ARARAQUARA - SP, BRASIL
}

\begin{abstract}
Resumo
Nas últimas décadas, a pesquisa no campo das políticas públicas tem mostrado que a ação de indivíduos (ou grupos) denominados "empreendedores de políticas públicas" constitui um aspecto central no processo de produção de políticas. Com base na análise da bibliografia teórica mais recente, este estudo tem por objetivo analisar o conceito de empreendedor de políticas públicas, investigando o papel desse importante ator em três modelos teóricos: o modelo de múltiplos fluxos de John Kingdon, o modelo de equilíbrio pontuado de Baumgartner e Jones e o modelo de coalizões de defesa de Sabatier e Jenkins-Smith. A análise mostra que há duas dimensões fundamentais na atuação dos empreendedores. Em primeiro lugar, esses atores assumem um papel importante na defesa das ideias relacionadas à definição dos problemas e à estruturação dos debates a respeito de soluções. Em segundo lugar, o empreendedor é um elemento essencial nos mecanismos explicativos sobre mudanças rápidas dos modelos de Kingdon e Baumgartner e Jones. Assim, o estudo explora as características do conceito de empreendedor de políticas públicas nesses modelos teóricos, bem como aponta os limites e contribuições do conceito para a compreensão do processo de produção de políticas públicas.
\end{abstract}

Palavras-chave: Políticas públicas. Empreendedores de políticas públicas. Mudanças em políticas públicas. Formação da agenda.

\section{A study on the concept of public policy entrepreneur: Ideas, Interests, and Changes}

\begin{abstract}
Over the last decades, research in the public policy field has shown that the action of individuals (or groups) named as "public policy entrepreneurs" constitutes a central aspect in the policy-making process. Based on the most recent theoretical bibliography, this study aims to analyze the concept of public policy entrepreneur, by addressing the role of this significant player in three theoretical models: John Kingdon's multiple streams model, Baumgartner and Jones' punctuated equilibrium model, and Sabatier and Jenkins-Smith's advocacy coalition framework). The analysis shows there are two crucial dimensions in entrepreneur's action. First, these players take a major role in advocating for the ideas related to defining problems and structuring debates about solutions. Second, the entrepreneur is an essential element in the explanatory mechanisms about rapid changes in the models by Kingdon and Baumgartner and Jones. Thus, the study explores the features of the concept of public policy entrepreneur in these theoretical models, and it also points out the limits and contributions of the concept to grasp the public policy-making process.
\end{abstract}

Keywords: Public policies. Public policy entrepreneurs. Public policy changes. Agenda formation.

\section{Un Estudio acerca del concepto de emprendedor de políticas públicas: Ideas, Intereses y Cambios}

\section{Resumen}

En las últimas décadas, la investigación en el ámbito de las políticas públicas ha mostrado que la acción de individuos (o grupos) llamados "emprendedores de políticas públicas" constituye un aspecto central del proceso de producción de políticas. Con base en el análisis de la bibliografía teórica más reciente, este estudio tiene como objetivo analizar el concepto de emprendedores de políticas públicas, mediante la investigación del papel de este importante actor en tres modelos teóricos: el modelo de flujos múltiples de John Kingdon, el modelo de equilibrio puntuado de Baumgartner y Jones y el modelo de coaliciones de defensa de Sabatier y Jenkins-Smith. El análisis muestra que hay dos dimensiones fundamentales en la acción de los emprendedores. En primer lugar, estos actores juegan un papel importante en la defensa de ideas relacionadas con la definición de los problemas y la estructuración de los debates acerca de soluciones. En segundo lugar, el emprendedor es un elemento crucial en los mecanismos explicativos sobre cambios rápidos en los modelos de Kingdon y Baumgartner y Jones. Así, el estudio tiene como objetivo explorar las características del concepto de emprendedor de políticas públicas en estos modelos teóricos, así como señalar los límites y las contribuciones del concepto para comprender el proceso de producción de políticas públicas.

Palabras clave: Políticas públicas. Emprendedores de políticas públicas. Cambios en políticas públicas. Formación de la agenda. 


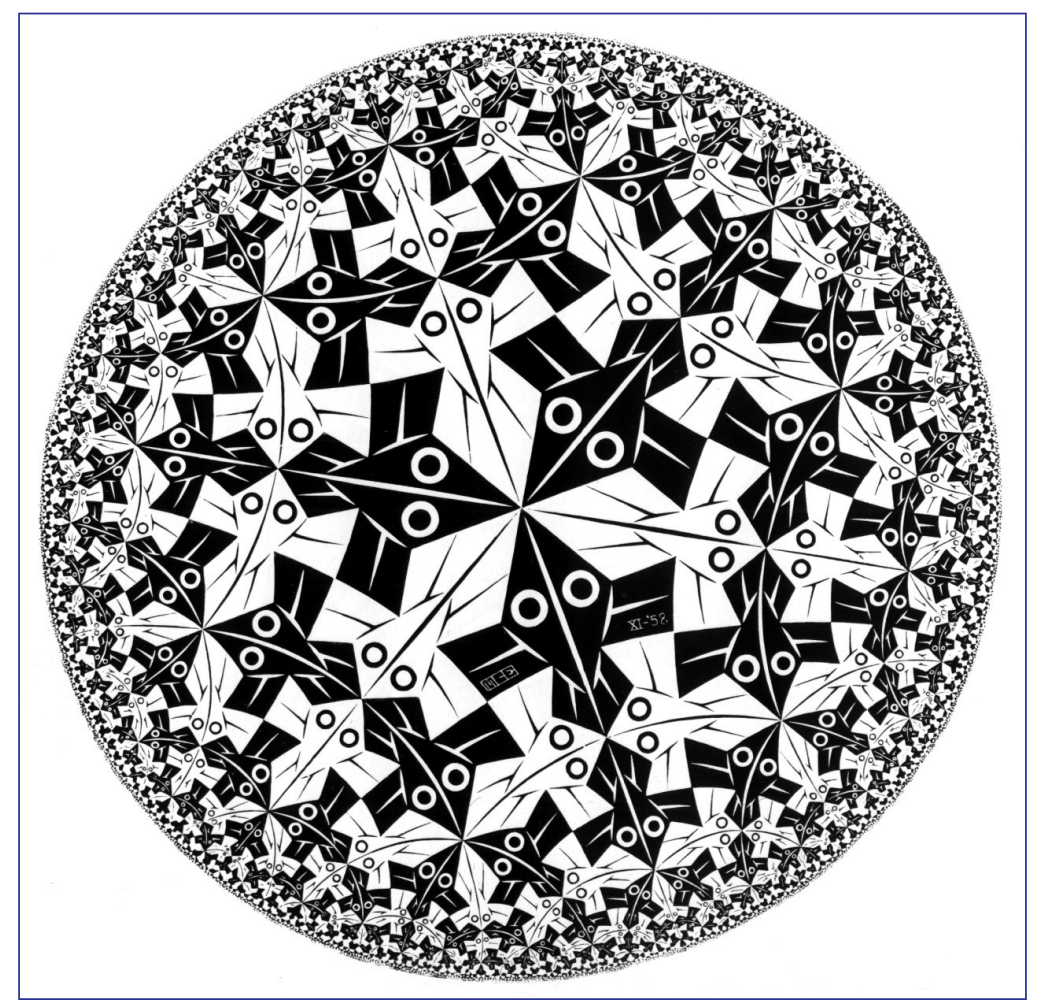

\section{INTRODUÇÃO}

O objetivo deste trabalho é apresentar e discutir um tipo particular de ator envolvido no processo de produção de políticas públicas: o empreendedor de políticas (policy entrepreneur). Nas últimas décadas, estudos desenvolvidos sobre a produção de políticas públicas - especialmente aqueles dedicados à formação da agenda (agenda-setting) - têm destacado o papel central que empreendedores de políticas desempenham. Embora os empreendedores sejam compreendidos de maneira diferente nesses estudos, sua atuação é considerada essencial em dois importantes aspectos: na defesa e difusão de ideias relativas a uma política e em processos de mudança em políticas públicas. Analisar o conceito de empreendedores de políticas, assim como a utilização deste conceito em modelos teóricos de políticas públicas, verificando seus limites e desafios enquanto ferramentas explicativas, constituem as preocupações centrais deste trabalho.

Os estudos sobre a ação de empreendedores têm sido realizados há algumas décadas em áreas como administração, economia e ciência política com relativo destaque. Temática frequente em estudos sobre organizações (públicas ou privadas) e comportamento organizacional, as análises sobre o empreendedorismo se expandem no mesmo ritmo em que o conceito se torna cada vez mais impreciso (MARTES, 2010). Embora não constitua objetivo deste trabalho resgatar os usos conceituais do termo "empreendedor", tampouco realizar uma profunda investigação sobre as definições apresentadas na literatura, é importante, para nossos propósitos, entender que o termo carrega alguns sentidos já bastante conhecidos na literatura especializada. Em especial, cabe destacar a relação entre a ação do empreendedor, suas crenças e a inovação.

É por meio da obra de Joseph Schumpeter que a noção do indivíduo empreendedor se difunde para diferentes áreas das ciências sociais. Para o autor, o empreendedor é aquele que altera a ordem econômica existente por meio da "destruição criativa" (SCHUMPETER, 1984). Para o autor, o empreendedor não é necessariamente alguém que investe o capital inicial ou inventa um novo produto, mas sim o indivíduo que tem uma ideia. Qualquer indivíduo pode apresentar ideias engenhosas: a diferença é que, nas mãos de empreendedores, essas ideias se tornam poderosas e lucrativas. A noção de um indivíduo

* Fonte da imagem: Disponível em <http://uploads4.wikiart.org/images/m-c-escher/circle-limit-i.jpg> Acesso em 18 mar. 2016. 
empreendedor está relacionada com o conceito de inovação, que significa "fazer as coisas de forma diferente". O empreendedor, com suas motivações, capacidade e imaginação, percebe as oportunidades para a inovação e a materializa. Tais inovações, segundo Schumpeter (1982), processam-se por meio da introdução de um novo produto, de um novo método de produção, de novos mercados, de novas fontes de matérias-primas, ou da reorganização de uma indústria. Desta forma, o empreendedor consegue mover a economia de um estado de equilíbrio e rotina para a mudança, "destruindo criativamente" as formas conhecidas e estabelecendo o novo. As mudanças realizadas por um empreendedor disseminam-se, sendo seguidas por outros empreendedores e, desta forma, o equilíbrio é rompido. Na teoria de Schumpeter, a presença de empreendedores é, portanto, fundamental ao desenvolvimento econômico, uma vez que estes atores buscarão sempre a inovação.

O conceito schumpeteriano de empreendedor foi posteriormente deslocado do mercado para o mundo da política. Estimulado pelas discussões relativas à lógica da ação coletiva, o economista Richard Wagner (1966) aplicou o termo "empreendedor político" (political entrepreneur) para designar indivíduos que empregam tempo, energia e recursos financeiros não apenas porque se importam com os objetivos de um grupo, mas também porque percebem uma oportunidade de transformar esse investimento em algo pessoalmente gratificante (SHEPSLE, 2008). Poucos anos depois, o próprio Olson, autor de "A Lógica da Ação Coletiva" reconhece o papel do empreendedor político na coordenação dos esforços de forma a promover benefícios coletivos. Para Olson (1999, p. 190), a ação coletiva em alguns grupos depende do provimento de benefícios seletivos, e o empreendedor político teria capacidade de produzir tais benefícios junto aos grupos, incentivando, dessa forma, a cooperação. Outra importante contribuição para a ideia do empreendedor político foi desenvolvida pelo cientista político Russell Hardin (1982), que aprofundou a investigação sobre as características do empreendedor político. Para ele, o empreendedor viabiliza a ação coletiva por meio de sua expertise, conhecimento e um timming sobre o momento certo de agir, percebendo o potencial para a ação coletiva, que não se realizaria sem sua intervenção. Além disso, o empreendedor político atua conectando os interesses público e privado em uma ação política, na provisão de bens coletivos. Nesse processo, o empreendedor não só ajuda ao grupo a obter um benefício coletivo que lhe seja necessário, mas também captura parte desse benefício para si. Embora compartilhe algumas características com o conceito original de Schumpeter, a noção de empreendedor político diferencia-se, sobretudo, por não relacionar-se, necessariamente, a processos de mudança. Empreendedores políticos podem atuar tanto no sentido da mudança quanto da estabilidade quando esta lhe interessa, mantendo privilégios, status ou outros recursos.

Mais recentemente, o conceito de empreendedor também tem sido empregado no campo dos estudos organizacionais. 0 conceito de empreendedor institucional (institutional entrepreneur) é associado aos estudos de Paul DiMaggio (1988), no contexto no novo institucionalismo organizacional. Para o autor, o empreendedor é um ator que persegue seus interesses de maneira intencional, promovendo alterações nos arranjos institucionais. Nessa perspectiva, novas instituições - ou mudanças em instituições já existentes - seriam o produto da ação de indivíduos munidos de recursos e que percebem a oportunidade de realizar seus próprios interesses DiMaggio (1988, p. 14). Tais recursos envolvem habilidades analíticas, políticas e culturais que permitam ao empreendedor mobilizar aliados, desenvolver novas alianças e estimular a cooperação de outros atores com suas ideias. De forma geral, a literatura sobre o empreendedor institucional destaca a dimensão discursiva, ou seja, ressalta a importância da linguagem e o desenvolvimento de narrativas por meio das quais o empreendedor veicula crenças e valores de forma a obter apoio para seus projetos. Buscando aprofundar a definição de DiMaggio, Battilana, Leca et al. (2009) propõem uma definição que pontua dois aspectos fundamentais da ação do empreendedor. Para os autores, o empreendedor é o agente que inicia processos de mudança que rompem com a configuração institucional existente, além de participar ativamente do processo de implementação dessa mudança. Assim, para os autores, o empreendedor institucional aproxima-se do conceito inicial do Schumpeter, ao inovar e provocar rompimentos com a ordem institucional existente. Por outro lado, a participação do empreendedor na implementação requer um conjunto de recursos e habilidades analíticas, políticas e culturais que favoreçam sua movimentação por contextos sociais específicos, mobilizando outros atores para participarem do processo de mudança.

Na literatura de políticas públicas, a ação do empreendedor de políticas (policy entrepreneur) tem ganhado destaque desde meados dos anos 1980. Um dos primeiros trabalhos a apontar a centralidade da ação do empreendedor em processos de rápida mudança em políticas públicas foi realizado por John Kingdon (2003). O modelo de Kingdon é voltado para a análise de dois processos: formação da agenda e especificação de alternativas, ou seja, momentos anteriores à tomada de decisão e à implementação das políticas públicas (KINGDON, 2003, p. 2-3) ${ }^{1}$. Na primeira seção, analisaremos como a figura do empreen-

${ }^{1}$ O modelo tem sido debatido pelos estudiosos, desde sua primeira apresentação em 1984, com relação a diversos aspectos teóricos e metodológicos e alguns autores têm apontado a possibilidade de extensão das ideias de Kingdon para outros momentos do "ciclo de políticas públicas", como o processo decisório 
dedor de políticas é apresentada no modelo de múltiplos fluxos (multiple streams model), destacando o papel central que esse ator ocupa no mecanismo explicativo do modelo. Depois, examinaremos o papel reservado ao empreendedor no modelo de equilíbrio pontuado (punctuated equilibrium model), de Frank Baumgartner e Bryan Jones (1993), que procura explicar tanto a estabilidade quanto as mudanças nas políticas públicas. Este modelo teórico concentra seu poder explicativo sobre a formação da agenda governamental, incorporando alguns dos conceitos desenvolvidos anteriormente por Kingdon e ampliando a análise sobre processos de mudança e estabilidade na agenda. Procuraremos compreender, ainda, como o modelo de coalizões de defesa (advocacy coalitions framework), proposto por Paul Sabatier e Jenkins-Smith (1993), pode contribuir para o entendimento das funções do empreendedor, muito embora o modelo não atribua a ele uma posição de centralidade. Esse modelo oferece uma visão integrada dos diferentes estágios do ciclo de políticas públicas, não sendo orientado à análise de nenhuma fase em particular, embora tenha sido aplicado, por vezes, em fases específicas, incluindo a fase de formação da agenda (WEIBLE, SABATIER e McQUEEN, 2009). Assim, na terceira seção, buscaremos explorar as contribuições do modelo para o entendimento da ação individual nos processos de políticas públicas. Em seguida, partiremos para a análise dos dois principais papéis do empreendedor de políticas públicas: a defesa de ideias e a inovação e mudança nas políticas públicas. Cada um dos modelos, como veremos, acrescenta dimensões importantes à ação do empreendedor e seus efeitos sobre o processo de políticas públicas. Por fim, algumas considerações sobre a ação dos empreendedores e sua influência na produção de políticas são apresentadas.

\section{EMPREENDEDORES NA FORMULAÇÃO DE POLÍTICAS PÚBLICAS}

Os empreendedores de políticas assumem papel central no modelo de múltiplos fluxos (multiple streams) desenvolvido por John Kingdon (2003). Para o autor, os empreendedores são indivíduos (eventualmente pequenos grupos de pessoas) cuja principal característica consiste na defesa de uma ideia e na percepção de momentos oportunos para conectar ideias a respeito de problemas e soluções, produzindo mudanças em políticas públicas.

Estes empreendedores podem estar posicionados em qualquer lugar de uma comunidade de políticas, tanto dentro quanto fora do governo, e investem seus recursos (tempo, energia, reputação, recursos financeiros) na defesa de determinadas propostas com base numa expectativa de ganhos futuros. Esses ganhos envolvem, de acordo com o autor, três tipos benefícios distintos. O primeiro grupo de benefícios se traduz em ganhos concretos e pessoais para o defensor de uma ideia. São incentivos materiais advindos das mudanças proporcionadas por suas ideias numa determinada política. Como exemplos de benefícios materiais, Kingdon (2003, p. 123) menciona a manutenção e expansão de orçamentos, funcionários e programas para os burocratas; benefícios eleitorais para os políticos; e proteção dos interesses dos membros de um grupo para lobistas. Outro tipo de benefício é caracterizado pela promoção de determinados valores numa política. São os benefícios intencionais, baseados em ideologias a respeito, por exemplo, do papel do Estado na economia. O terceiro tipo de ganho que o empreendedor pode ter são os chamados benefícios solidários, que advêm do prazer de se engajar na defesa de ideias: "some entrepreneurs simply like the game. They enjoy advocacy, they enjoy being at or near the seat of power, they enjoy being part of action" (KINGDON, 2003, p. 123).

Três características são destacadas por Kingdon com relação às qualidades de um empreendedor. Em primeiro lugar, são indivíduos que têm crédito frente a uma audiência, ou seja, detêm legitimidade possivelmente devido a fatores como a especialidade no assunto em questão (expertise), a habilidade na comunicação, ou sua posição formal no processo decisório. A segunda característica do empreendedor está relacionada às conexões políticas e habilidades de negociação desses indivíduos. Por fim, a persistência é apontada pelo autor como a terceira característica vital para a atividade do empreendedor, implicando a disponibilidade de investimento de grandes quantidades de recursos pessoais. "Most of these people spend a great deal of time giving talks, writing position papers, sending letters to important people, drafting bills, testifying before congressional committees and executive branch commissions, and having lunch, all with the aim of pushing their ideas in whatever way and forum might further the cause" (KINGDON, 2003, p. 181). Essas qualidades são úteis nas duas frentes de

(ZAHARIADIS, 1989) e implementação (RIDDE, 2009). Neste estudo, manteremos o foco na fase de formação da agenda e especificação de alternativas, tal como formulado por Kingdon (2003). 
atuação dos empreendedores no modelo de Kingdon: na promoção das ideias, propostas e concepções a respeito de problemas e no momento em que surge a oportunidade de mudança na agenda.

Sejam movidos por interesses pessoais, valores, ou pela própria satisfação em participar do processo, os empreendedores, para Kingdon, promovem suas ideias em comunidades de políticas (policy communities), compostas por especialistas numa área temática. Estes especialistas, que podem pertencer ou não aos quadros governamentais, compartilham uma preocupação com uma área específica de políticas e interagem em comunidades, conhecem os demais membros, suas propostas e ideias. Um dos papéis fundamentais desempenhado pelos empreendedores de políticas no modelo de Kingdon é o processo de apresentação das ideias em tais comunidades, uma vez que é nelas que as propostas sobre o que fazer numa dada área de política são apresentadas e disseminadas por seus participantes. As comunidades, para Kingdon, tendem a ser resistentes às mudanças, e a atividade de apresentação e discussão de determinadas ideias é fundamental para ampliar as chances de aceitação de novas propostas. Os empreendedores também levam as ideias para além dos limites das comunidades, buscando apresentá-las para o público em geral, de forma a acostumar as pessoas às propostas. Este trabalho de argumentação e defesa de ideias é desenvolvido por meio de diferentes formas: políticos podem introduzir um projeto de lei para confrontar as pessoas com uma ideia, da mesma forma que a realização de audiências públicas pode servir para a discussão prévia de propostas. Burocratas podem apresentar ideias realizando palestras e conferências pelo país, elaborando e divulgando estudos e relatórios. Muitas vezes, o empreendedor apenas testa a receptividade de uma ideia junto ao público em geral e no interior das comunidades. Para o autor, esse processo por vezes se assemelha ao lançamento de balões de ensaio: "A bureaucrat tries out an idea by slipping a paragraph into a secretary's speech to see what the reaction is. Or a senator introduces a bill, not because it will pass that year but because he tests the water and gauges the state of receptivity to an idea". (KINGDON, 2003, p. 129). Ideias apresentadas desta maneira podem não sobreviver, mas ajudam a concentrar a atenção das pessoas em determinados assuntos. Para Kingdon, esse processo inicial em que diversas ideias são testadas parece ser necessário para que uma questão seja considerada de maneira mais séria: “Many good proposals have fallen on deaf ears because they arrived before the general public, the specialized publics, or the policy communities were ready to listen. Eventually, such a proposal might be resurrected, but only after a period of paving the way (KINGDON, 2003, p. 130).

Além da promoção das ideias, os empreendedores desempenham um papel crítico no modelo de Kingdon, mais diretamente relacionado com a mudança na agenda governamental. No modelo de agenda-setting do autor, a mudança na agenda governamental é resultado de uma complexa combinação de fatores, incluindo a forma pela qual um problema é percebido, as possibilidades de utilização de um conjunto de soluções disponíveis e as alterações na dinâmica política e da opinião pública. Cada uma das três dimensões (chamadas pelo autor de fluxos ou streams) desenvolve-se de maneira relativamente independente em relação às demais, cada qual regida por sua própria lógica. Do primeiro fluxo, fazem parte as questões que foram reconhecidas como problemas e passaram a ocupar a agenda governamental. Considerando o grande volume de decisões e a incapacidade de lidar com todas as questões ao mesmo tempo, a atenção dos formuladores de políticas depende da forma como eles as percebem e as interpretam e, mais importante, como essas questões são definidas enquanto problemas. Alguns mecanismos, como indicadores produzidos sistematicamente (monitoramento de programas governamentais, relatórios de desempenho) e principalmente grandes eventos (desastres, catástrofes, grandes acidentes), contribuem para focalizar a atenção sobre uma questão. No entanto, esses mecanismos não transformam as questões automaticamente em problemas. A interpretação desses eventos e seu entendimento enquanto problemas que demandam ação governamental são fundamentais para o sucesso de uma questão na agenda. No segundo fluxo, um conjunto de possíveis alternativas para os problemas são desenvolvidos por especialistas (pesquisadores, assessores parlamentares, acadêmicos, funcionários públicos, analistas pertencentes a grupos de interesses, entre outros). Essas alternativas, não necessariamente relacionadas à percepção de problemas específicos, circulam por comunidades de experts, e, enquanto algumas são descartadas, outras sobrevivem, podendo chegar à consideração de atores governamentais com autoridade e capacidade para tomar decisões em uma política. Por fim, o terceiro fluxo é composto pela dimensão da opinião pública (percepção geral sobre determinadas questões), das forças políticas organizadas (posicionamento dos grupos de interesse em relação a uma questão, por exemplo) e do próprio governo (mudança de pessoas em posições estratégicas dentro da estrutura governamental, mudanças de gestão, mudanças na composição do Congresso, entre outros fatores).

Em determinadas circunstâncias, estes três fluxos - problemas, soluções e dinâmica política - podem convergir, criando uma possibilidade concreta de mudança na agenda governamental. Em tais oportunidades (denominadas pelo autor como policy 
windows), um problema é reconhecido, uma solução está disponível, e as condições políticas tornam o momento propício para a mudança, permitindo a integração dos três fluxos e possibilitando que questões ascendam à agenda. Neste momento, o empreendedor deve estar pronto, uma vez que o modelo de Kingdon reserva a ele a responsabilidade por operar a conexão entre os três fluxos (processo chamado pelo autor de coupling) e, portanto, de facilitar o acesso de uma questão à agenda.

Essas oportunidades são, no entanto, transitórias. Algumas delas são mais ou menos previsíveis (como o momento altamente favorável às mudanças geralmente associado ao início de um novo governo), e a tarefa do empreendedor consiste em desenvolver as ideias e propostas a respeito de uma política antes que a oportunidade se apresente. Neste aspecto, o autor compara o empreendedor a um "surfista esperando pela grande onda", equilibrando seu senso de oportunidade e destreza com as forças externas. Indivíduos não têm poder de controlar as ondas, assim como não podem controlar eventos e estruturas. No entanto, podem se equilibrar sobre as ondas, da mesma forma como podem antecipar oportunidades e tirar proveito destas. Assim, na busca de seus propósitos, os empreendedores unem soluções, problemas e contexto político, aproveitando as oportunidades que se apresentam e operando um papel central no modelo de multiple streams, como afirma Kingdon (2003, p. 182): "Without the presence of an entrepreneur, the linking of the streams may not take place. Good ideas lie fallow for lack of an advocate. Problems are unsolved for lack of a solution. Political events are not capitalized for lack of inventive and developed proposals".

O modelo de Kingdon, portanto, reserva especial destaque para a ação do empreendedor. No entanto, o próprio autor adverte que os empreendedores não controlam os processos de mudança. O processo pelo qual a mudança na agenda se efetiva é influenciado por grandes eventos e pelas estruturas e não pela vontade de um indivíduo em particular.

\section{O PAPEL DOS EMPREENDEDORES NA MUDANÇA E NA ESTABILIDADE DAS POLÍTICAS PÚBLICAS}

Para Baumgartner e Jones (1993), autores que propuseram o modelo do equilíbrio pontuado (punctuated equilibrium model), analisar a atuação dos empreendedores também é essencial para a compreensão das mudanças numa política. Os autores desenvolvem o conceito de empreendedor, seguindo o trabalho sobre agenda-setting desenvolvido por John Kingdon (2003) e com base nos estudos sobre manipulação política de William Riker (1986).

Do estudo de Kingdon (2003), Baumgartner e Jones destacam a importante atuação do empreendedor como sendo o responsável pela conexão de soluções e problemas. Para os autores, da mesma forma que na abordagem de multiple streams, problemas não estão necessariamente ligados a soluções no processo de produção de uma política. E uma das tarefas fundamentais do empreendedor consiste em demonstrar que suas soluções representam a melhor resposta para um novo problema, quando os formuladores de política estão debruçados sobre uma determinada questão. Mesmo que a solução seja preexistente ao problema ou mesmo que não tenha nenhuma relação mais direta com tal problema, cabe ao empreendedor argumentar e criar novos entendimentos sobre a questão para favorecer sua visão. "The trick for a policy entrepreneur is to ensure that the solution he or she favors is adopted once a given problem has emerged on the national agenda" (BAUMGARTNER e JONES, 1993, p. 29). A produção de políticas é influenciada não apenas pela redefinição de problemas mas pela redefinição simultânea das formas mais efetivas de lidar com as situações percebidas, ou seja, o empreendedor tem como tarefa definir problemas e apresentar soluções consideradas adequadas, como aponta Kingdon (2003).

Outra inspiração para o modelo provém do trabalho de Riker (1986), que desenvolve o conceito de heresthetics para designar ação política baseada na habilidade de alterar a estrutura de preferências e alternativas que incidem sobre o processo decisório de maneira a determinar as opiniões dos participantes. Para tanto, Riker mostra que a ação política pode envolver três formas de manipulação: controle sobre a agenda, voto estratégico e dimensionalidade. Estas três formas de manipulação envolvem tanto o controle das regras formais e a dimensão institucional do processo decisório, quanto os argumentos retóricos utilizados no debate, os entendimentos desenvolvidos em torno de uma questão. O estudo de Riker é fundamental para a construção do conceito de empreendedor de políticas em Baumgartner e Jones (1993), que destacam sua atuação tanto na dimensão institucional, por meio da criação e manutenção de um "monopólio de políticas" (policy monopolies) quanto da dimensão simbólica, na definição e disseminação da "imagem de uma política" (policy image).

O conceito de monopólio de políticas é desenvolvido por Baumgartner e Jones (1993) para designar um subsistema dominado por um único interesse. Duas características principais definem e constituem tais monopólios. Em primeiro lugar, o todo 
monopólio dispõe de uma estrutura institucional identificável, na qual o processo decisório relativo a uma política se desenvolve. Esses monopólios, reforçados por arranjos institucionais, mantêm o processo decisório limitado a um grupo pequeno de atores, restringindo o acesso dos demais. Em segundo lugar, os monopólios contam com uma ideia de apoio, uma imagem (policy image) associada a essa estrutura institucional. Assim, o conceito de monopólio de políticas representa um conjunto de entendimentos sobre uma determinada questão que se torna dominante e a partir do qual os atores passam a ter a habilidade de controlar a interpretação sobre um problema e a forma como este é percebido e discutido. Estes monopólios são responsáveis pela manutenção da estabilidade na produção de políticas públicas e restrição de novas questões à agenda governamental. Mudanças nas políticas ocorrem quando os monopólios se desestruturam. Assim, uma das ações mais importantes dos empreendedores consiste na criação e manutenção de um monopólio de políticas, para que o sistema político se mantenha estável em torno de algumas questões. O empreendedor, para os autores, é o indivíduo que procura agir de forma com que o governo faça algo numa determinada política ou, por outro lado, deixe de fazer (BAUMGARTNER e JONES, 1993, p. 23). O estabelecimento de um monopólio é um dos fatores determinantes para a estabilidade do sistema político, e um dos interesses mais fortes dos atores interessados na manutenção do status quo. Para os autores,

Every interest, every group, every policy entrepreneur has a primary interest in establishing a monopoly - a monopoly on political understandings concerning the policy of interest, and an institutional arrangement that reinforces that understanding. Nobody likes protracted conflict and continual competition. Much preferable to a system of constant conflict is one where each side retreats into a given area where its influence is uncontested. (BAUMGARTNER e JONES, 1993, p. 06).

Os monopólios de políticas são elementos que proporcionam equilíbrio e estabilidade aos sistemas políticos, situação que pode perdurar por longos períodos. No entanto, o mesmo mecanismo empregado para explicar a estabilidade produz explicações também sobre as mudanças que se processam, muitas vezes, de forma rápida (e não de maneira incremental). Tais rupturas, ou pontuações, decorrem de mudanças no equilíbrio previamente induzido pelos monopólios. A destruição de um monopólio geralmente relaciona-se com a mobilização de atores previamente afastados do processo decisório. Enquanto uma visão compartilhada sobre símbolos, problemas, soluções e relações causais prevalecer a respeito de uma determinada política (ou seja, enquanto a imagem de uma política permanecer inalterada), o monopólio se sustenta, restringindo o acesso ao processo decisório daqueles atores que não concordam com essa imagem. Tem-se, então, a prevalência de mudanças lentas, graduais e incrementais, configurando uma situação de equilíbrio na produção das políticas públicas. No entanto, em alguns momentos, novos atores conseguem acesso aos "monopólios", criando instabilidade e a oportunidade de mudança na agenda. Isso acontece, segundo os autores, por causa de mudanças na forma como uma questão é compreendida, ou seja, por meio de alterações na imagem de uma política. Mudanças na percepção das questões, acontecimentos que focalizem atenção do governo, alterações na opinião pública, por exemplo, podem contribuir para a alteração na imagem de uma política, permitindo o acesso de diferentes grupos ao processo decisório e, desta forma, favorecendo o ingresso de uma questão na agenda governamental. Quando uma questão ascende à agenda, o monopólio deixa de existir e o sistema torna-se propenso à mudança, já que a atenção dos líderes governamentais e do público pode levar à introdução de novas ideias e de novos atores. As novas ideias e instituições tendem a permanecer ao longo do tempo, criando um novo estado de equilíbrio no sistema político que, após um período, tende a voltar à estabilidade.

Para Baumgartner e Jones, portanto, uma das principais ações do empreendedor consiste na definição e redefinição das questões, ou seja, na criação e manutenção de uma representação simbólica a respeito de uma política. Neste sentido, a construção do conceito de empreendedor para os autores se aproxima do entendimento sobre o empreendedor presente no modelo de Kingdon. O empreendedor é o indivíduo que entende a importância das ideias no processo político e as promove de maneira a convencer os demais atores com relação a uma questão. No caso da mudança da agenda, os empreendedores buscam redefinir as questões de forma a torná-la atrativa aos grupos previamente apáticos e, caso estes grupos escolham ingressar na disputa política, podem desorganizar os monopólios existentes. A base da mobilização baseia-se, segundo Baumgartner e Jones, no entendimento compartilhado pelos indivíduos sobre uma questão. Os empreendedores, atuando na criação e divulgação de imagens, conseguem mobilizar os atores e criar ou desorganizar monopólios. Com a atenção que conseguem mobilizar, a partir da alteração da imagem de uma política, os empreendedores procuram assegurar, rapidamente, junto ao governo, arenas institucionais com maiores chances de sucesso para o desenvolvimento do processo decisório relativo às decisões referentes à política em questão. O objetivo dos empreendedores é sempre estabelecer um monopólio para tal política. 
Embora os autores não especifiquem, como Kingdon, as formas de atuação dos empreendedores, no processo de redefinição das questões, adicionam um importante ingrediente às explicações deste, pois mostram que, além de desempenharem papel central no estabelecimento e divulgação sobre determinados entendimentos sobre uma política, também buscam arenas políticas mais favoráveis para suas ideias (policy venues). "Images and venues are closely associated with each other. Policymakers attempt both to manipulate the dominant understanting of the issues with they deal and to influence the institutions that exert jurisdiction over them (...) So the searches for favorable venues and reinforcing images are related" (BAUMGARTNER e JONES, 1993, p. 35). Os autores denominam policy venues às instituições ou grupos com autoridade para tomar decisões relativas a uma política. Uma mesma questão pode ser objeto das decisões de uma única instituição ou de diversas delas ao mesmo tempo. Além disso, em cada instituição, uma mesma questão pode receber atenção e apoio de forma diferenciada: "Each institutional venue is home to a different image of the same question" (BAUMGARTNER e JONES, 1993, p. 31). Determinadas definições de uma política são mais bem aceitas em um grupo do que em outro, e cabe especialmente ao empreendedor buscar arenas institucionais nas quais uma ideia possa prosperar. O sistema federalista é apontado pelos autores como característica do sistema político que aumenta as oportunidades dos empreendedores, uma vez que estes dispõem de arenas distintas para a experimentação de suas ideias (BAUMGARTNER e JONES, 1993, p. 216). Um empreendedor que não obtenha sucesso no convencimento das pessoas sobre um determinado problema no plano federal, por exemplo, pode (e os autores mostram que frequentemente o faz) buscar no plano estadual ou local o apoio para suas ideias.

Assim, a força fundamental para a explicação tanto da manutenção de uma agenda, quanto de sua mudança é, precisamente, a imagem das políticas públicas, considerada um elemento crucial na luta política. O processo de agenda-setting, para os autores, consiste em alocar a atenção governamental para alguns assuntos específicos e, neste processo, as alterações na forma como uma questão é definida podem levar a mudanças no nível de atenção que as questões recebem dos formuladores de políticas. O papel do empreendedor é central nesse processo, por meio da estruturação (ou rompimento) dos monopólios (baseados em imagens específicas sobre uma política e seu respectivo arranjo institucional), somada à possibilidade de percorrer diferentes arenas em busca de melhores oportunidades para suas ideias.

\section{COALIZÕES, APRENDIZADO E A AUSÊNCIA DO EMPREENDEDOR}

Embora o modelo das Coalizões de Defesa (Advocacy Coalition Framework) não se concentre especificamente no papel dos empreendedores de políticas, há interpretações que mostram que o modelo reserva espaço para a atuação de indivíduos tanto na formação quanto na manutenção das coalizões (MINTROM e VERGARI, 1996). Este papel seria exercido principalmente por meio da representação estratégica de problemas, influenciando o sistema de crenças compartilhado por uma coalizão (MINTROM e NORMAN, 2009). Desta forma, teríamos uma atuação bastante semelhante ao desempenhado pelo empreendedor nos modelos de Kingdon e de Baumgartner e Jones.

As análises de Sabatier e Jenkins-Smith (1993) sobre as mudanças nas políticas baseiam-se no entendimento das políticas públicas como um sistema de crenças. Segundo os autores, políticas e programas de governo incorporam teorias implícitas sobre como atingir seus objetivos, envolvendo valores, percepções sobre causas e efeitos, entendimentos sobre a eficácia dos instrumentos políticos, entre outras. Tais crenças constituem a base de funcionamento dos subsistemas, unidade de análise privilegiada pelo modelo. Os subsistemas - conjunto de pessoas e organizações que interagem de maneira sistemática durante um período de tempo para influenciar uma determinada política - são compostos por atores de todos os níveis de governo além de outros atores externos à estrutura governamental. Tais atores permanecem unidos por meio do compartilhamento de crenças em comum e do empenho em ações coordenadas em torno de uma política, formando assim verdadeiras "coalizões de defesa".

O conjunto de crenças que sustenta as coalizões forma um sistema mais ou menos hierarquizado, no qual crenças abstratas são mais evidentes e resistentes à mudança dos que as crenças mais específicas. Num plano mais geral e abstrato estão as deep core beliefs, que incluem valores ontológicos e normativos, sendo este tipo de crença altamente resistente à mudança. Abaixo destas, estão as policy core beliefs, um pouco menos rígidas que as primeiras, e que representam as percepções comuns sobre o subsistema e os valores compartilhados sobre a política de interesse desse subsistema. Os autores entendem que estas crenças sobre a política são fundamentais para a sobrevivência dos próprios subsistemas. Finalmente, um 
terceiro componente são crenças mais específicas, relacionadas à visão do problema e às relações causais entre eles, bem como o desenho das instituições, avaliação do desempenho dos atores e alocações orçamentárias. Alterações neste grupo de crenças secundárias representam mudanças de pequeno impacto. As coalizões, desta forma, mantêm-se unidas em torno de crenças que orientam sua ação no processo de produção das políticas.

De acordo com o modelo, no interior de cada subsistema podemos encontrar coalizões (geralmente entre duas e quatro coalizões) que compartilham crenças e que, em determinados momentos, adotam estratégias diferentes para realizar seus objetivos de mudança. A escolha de estratégias conflitantes entre coalizões de um mesmo subsistema gera uma situação de competição em que a atuação de mediadores torna-se fundamental para reduzir o conflito. Esses mediadores, chamados policy brokers, são agentes políticos que atuam como intermediários no conflito entre as coalizões.

Not everyone active in a policy subsystem will belong to an advocacy coalition or share the major belief systems. (...). In addiction, there will almost certainly be a category of actors - here termed policy brokers - whose dominant concerns are with keeping the level of political conflict within acceptable limits and reaching some reasonable solution to the problem. This is a traditional function of some elected officials and (...) of high civil servants. (SABATIER e JENKINS-SMITH, 1993, p. 27)².

Uma característica importante dos policy brokers reside na diferenciação que os autores estabelecem entre este ator e aqueles que atuam na defesa de uma política. Um indivíduo preocupado em defender uma política terá preocupações relacionadas com a manutenção do sistema, enquanto o policy broker pode tolerar algumas modificações na política caso estas reduzam o conflito entre as coalizões num subsistema. Além disso, um mesmo indivíduo atuando na defesa de uma política pode, eventualmente, assumir o papel de intermediário com as demais coalizões. Para os autores, "the framework merely insists that policy brokering is an empirical matter that may or may not correlate with institutional affiliation: While high civil servants may be brokers, they are also often policy advocates - particularly when their agency has a cleary defined mission". (SABATIER e JENKINS-SMITH, 1993, p. 27). Desta forma, o modelo não estabelece uma distinção muito clara entre os policy brokers e os membros das coalizões num subsistema, uma vez que estes não são vistos como agentes neutros e podem agir de acordo com os interesses de um grupo. Além de atuarem como mediadores, esses indivíduos também podem expressar posições mais próximas de determinada coalizão no interior de um subsistema (SABATIER e JENKINS-SMITH, 1993).

A mudança na política, para o modelo de coalizões de defesa, é explicada por meio de dois processos. Em primeiro lugar, a política muda em função da interação de coalizões em competição dentro de um subsistema. O resultado das escolhas realizadas pelas coalizões é a produção, pelos subsistemas, de políticas governamentais, gerando mudanças nas condições externas e alterando as expectativas e crenças sobre as consequências daquelas políticas. Este resultado altera também a ação das coalizões, num processo que, por meio da percepção de adequação das decisões governamentais, dos impactos produzidos, e de novas informações, gera um aprendizado constante.

A segunda fonte de mudanças numa política provém de mudanças externas ao subsistema de coalizões. Dois conjuntos de variáveis são apontados pelos autores como responsáveis por afetar os incentivos e restrições que se apresentam aos atores no interior dos subsistemas. O primeiro conjunto é composto por variáveis estáveis - mais difíceis de serem mudadas - e inclui regras institucionais, elementos da estrutura social, valores socioculturais fundamentais e recursos do sistema político. O segundo conjunto de variáveis agrupa elementos mais dinâmicos - mais facilmente alteradas - e é composto por grandes mudanças socioeconômicas, mudanças no sistema de coalizão governamental, bem como as decisões e impactos de outros subsistemas. As alterações, seja nos parâmetros estáveis ou nas variáveis dinâmicas, promovem incentivos para as mudanças nas políticas.

Assim, o modelo proposto por Sabatier e Jenkins-Smith compartilha algumas das características dos modelos previamente analisados. Em comum, rompe com a ideia de desenvolvimento de políticas como um processo sequencial e linear, no qual a identificação de um problema ensejaria a proposição de soluções. Também traz ao centro da análise a questão das ideias. Embora não se concentrem apenas no processo de formulação de políticas, os autores entendem que a mudança na agenda é fruto da dinâmica dessas ideias dentro das coalizões. Assim como o modelo de equilíbrio pontuado e o modelo de múltiplos fluxos, os autores enfatizam a ideia de subsistemas, nos quais as ideias se desenvolvem e são difundidas. 0 modelo das

\footnotetext{
${ }^{2}$ Grifos do original.
} 
coalizões de defesa proporciona o entendimento da dinâmica de interação dos atores unidos em coalizões. A arena institucional, que pode tanto limitar quanto incentivar a ação das coalizões, é componente importante do modelo, à semelhança do modelo de equilíbrio pontuado.

Com relação aos empreendedores de políticas, o modelo não trata especificamente deste tipo de ator. Papel diferente é reservado ao policy broker, que não apresenta as características dos empreendedores em Kingdon ou em Baumgartner e Jones. Uma das explicações para esta diferença reside no fato de que tanto o modelo de múltiplos fluxos quanto o modelo de equilíbrio pontuado lidam com processos de mudanças que ocorrem de forma rápida e dinâmica, enquanto o modelo de coalizões de defesa, baseando-se nas ações desenvolvidas de forma sistemática nos subsistemas por um período de, pelo menos, dez anos, tende a ver os eventos de curto prazo como mudanças incrementais. Por outro lado, há estudos que mostram a complementaridade entre a ideia de empreendedor e o modelo das coalizões de defesa. Mintrom e Vergari (1996) mostram que o modelo poderia ser aprimorado ao aprofundar as explicações sobre como as coalizões se formam. Neste aspecto, segundo os autores, a atuação do empreendedor seria fundamental, principalmente na definição das questões que mobilizam o apoio das coalizões. A inserção do empreendedor no modelo poderia ajudar a explicar a aproximação entre os membros das coalizões e também a coesão deles em torno de um conjunto de crenças. Assim, o empreendedor, para Mintrom e Vergari (1996), teria papel essencial na formação das coalizões, papel ainda não explorado pelo modelo. Outra possibilidade apontada pelos autores é que os empreendedores poderiam auxiliar as coalizões a obter suporte dos formuladores de políticas, favorecendo suas ações. Para os autores, desenvolver a análise sobre os empreendedores no modelo resultaria em explicações mais detaIhadas sobre o processo de produção de políticas.

\section{OS EMPREENDEDORES E A DEFESA DAS IDEIAS NAS POLÍTICAS PÚBLICAS}

Embora os empreendedores não sejam figuras recentes na literatura das ciências sociais, como vimos no início deste trabaIho, é certo que esses atores têm ocupado destaque crescente nos modelos teóricos em políticas públicas, principalmente em abordagens recentes que buscam explicar a formulação de políticas. Essas abordagens compartilham vários aspectos e, em particular, partem do princípio de que "ideias importam". Na verdade, esse é um movimento mais amplo que emerge ao longo dos anos 1990, quando pesquisadores de políticas públicas passaram a destacar os efeitos das ideias e do conhecimento na produção de políticas (FARIA, 2003). Para o campo das políticas públicas, essa perspectiva sinaliza uma mudança significativa em relação à chamada "perspectiva analítica" (analycentric turn), que predominou entre os anos de 1960 e 1980 , de caráter fortemente tecnocrático (DUNN, 1994).

Apesar disso, diferentes autores têm perspectivas distintas quanto ao que sejam exatamente as "ideias" ${ }^{3}$ e como lidar com elas do ponto de vista metodológico (JOHN, 1999; FARIA, 2003). Como afirma Faria (2003, p. 23):

As ideias podem ser definidas, por exemplo, como afirmação de valores, podem especificar relações causais, podem ser soluções para problemas públicos, símbolos e imagens que expressam identidades públicas e privadas, bem como concepções de mundo e ideologias.

Embora ainda não haja consenso na literatura sobre o conceito de "ideias", alguns autores têm se debruçado sobre o tema, procurando não apenas delimitar o conceito, mas também investigar o papel das ideias na produção de políticas públicas, sua relação com os interesses e outras dimensões fundamentais da vida política (BÉLAND e COX, 2011). Uma alternativa é apresentada por Campbell (1998; 2002) que, combinando elementos do novo institucionalismo histórico e organizacional, identifica quatro conceitos sobre o que são as ideias, além de buscar apontar os efeitos de cada um desses conceitos sobre o processo de produção de políticas públicas. O primeiro conceito apresentado pelo autor identifica ideias como "programas" ou prescrições sobre políticas que auxiliam os tomadores de decisão a definir um curso de ação com base em informações técnicas e profissionais. Ideias também podem ser entendidas como "enquadramentos" (frames), ou seja, como símbolos e conceitos utilizados pelos formuladores de política para legitimar as soluções perante o público. Ideias podem ser entendidas,

\footnotetext{
${ }^{3}$ As "ideias" podem ser entendidas, por exemplo, como "argumentação" e "retórica” para Fisher e Forester (1993) e para Majone (1989); como "símbolos" e "narrativas" para Stone (1997); e como "interpretação" para Yanow (1996).
} 
ainda, como "paradigmas" ou pressuposições mais gerais dos tomadores de decisão, que operam restringindo as alternativas disponíveis. Por fim, ideias podem ser compreendidas como "sentimentos públicos", ou pressuposições da sociedade que restringem a extensão das soluções consideradas legítimas pelos tomadores de decisão. Assim, os quatro conceitos são definidos em função de seus níveis mais ou menos visíveis, considerando desde valores e atitudes que formam o pano de fundo dos debates sobre as políticas, como no caso dos "paradigmas" e "sentimentos públicos", até ideias que estão em primeiro plano dos debates sobre as políticas, de forma mais explícita, como os "programas" e "enquadramentos". Também são privilegiadas duas dimensões: cognitiva, na qual as ideias são descrições e análises sobre relações de causa e efeito, como no caso dos "programas" e "paradigmas"; e normativa, em que as ideias consistem em valores e atitudes, como no caso dos "enquadramentos" e "sentimentos públicos" (CAMPBEL, 1998).

O entendimento sobre o que são as ideias - e sua relação com a atuação do empreendedor - no contexto dos modelos analisados reflete essas diferentes características. Para o modelo de múltiplos fluxos (KINGDON, 2003), as ideias estão relacionadas a entendimentos a respeito de problemas e de soluções, tanto na dimensão cognitiva quanto na dimensão normativa. Problemas recebem atenção em função da forma como são definidos, processo que envolve o enquadramento de questões (framming), ou seja, a maneira como certos temas são abordados; a atribuição de responsabilidades, por meio da definição de relações causais; a seleção e interpretação de indicadores relacionados às questões em debate (KINGDON, 2003, p. 90-91). Já as soluções são ideias que circulam nas comunidades de políticas, vindas dos mais diversos lugares. Ideias tecnicamente viáveis, aceitas pela comunidade e relacionadas a custos toleráveis tendem a ser mais bem-sucedidas no competitivo processo de seleção. O empreendedor é um indivíduo (ou um grupo de indivíduos) que busca apresentar aos tomadores de decisão informações a respeito de problemas e soluções, considerando que estes estão imersos num ambiente de ambiguidade e incerteza, não tendo clareza a respeito das questões com as quais estão envolvidos ${ }^{4}$. Nesse aspecto, o modelo de Kingdon entende o empreendedor como um ator envolvido com a manipulação - não apenas com a persuasão - dos tomadores de decisão.

Political manipulation is more than just persuasion and identity construction. Persuasion involves generating facts to change people's minds (...) MS [multiple streams] assumes that policy makers have not made up their minds, so there is little to be changed. In the absence of well-formed goals, more information is not the answer. The key is to understand how information is presented and processed. It's not enough to merely specify how identities or meanings are constructed, as constructivists ate content to do. While identity or meaning construction os a necessary condition, it is not sufficient to explain the fluctuation of policies over time. (ZACHARIDIS, 2007, p. 70).

Assim, o entendimento sobre as ideias, no modelo de Kingdon, ultrapassa a perspectiva construcionista sobre as ideias e aponta para uma relação muito mais próxima entre ideias e interesses. O empreendedor não apenas empenha-se em atividades de persuasão e construção de sentidos a respeito de problemas e soluções, mas também exerce um papel de manipulação política sobre os tomadores de decisão. Por outro lado, o empreendedor não é um sujeito racional, no sentido de comportar-se de forma oportunística para maximizar sua utilidade. O empreendedor pode ter seus objetivos e buscar manipular os tomadores de decisão, mas são estes últimos que determinam que uma solução é "boa o suficiente", ou seja, o modelo defende que a tomada de decisão é determinada politicamente - e não pelo empreendedor em função de seus próprios interesses. Como afirma Zachariadis (2007, p. 69), "the logical of political manipulation sets MS [multiple streams] apart from other lenses, which employ rationality (rational choice) or persuasion (constructivism)".

De forma bastante semelhante, o modelo do equilíbrio pontuado (BAUMGARTNER e JONES, 1993) relaciona ideias às estratégias de gerenciamento da atenção, elemento essencial para a definição de problemas. As ideias, nesse sentido, envolvem, assim como para Kingdon, o enquadramento de questões, processo em que os autores destacam a combinação entre informação empírica e apelo emocional (TRUE, BAUMGARTNER e JONES, 1999), explicitação de relações de causalidade, mensurações, além de símbolos e eventos catalisadores de atenção. Os autores também entendem as ideias como formas de perceber e lidar com as situações, ou seja, soluções adequadas aos problemas. As ideias, ou seja, o conjunto de entendimentos

\footnotetext{
${ }^{4}$ É importante lembrar que o processo de formação de agenda, tal como desenvolvido por Kingdon, tem suas raízes no "modelo da lata do lixo", proposto por Cohen, March e Olsen (1972). Este modelo foi desenvolvido para a análise de organizações que se configuram como "anarquias organizadas", operando em condições de grande incerteza e ambiguidade (como universidades e governos nacionais), nas quais estão presentes três características principais: participação fluída, preferências problemáticas e tecnologia pouco clara. Tais características organizacionais foram adaptadas por Kingdon como base de seu modelo teórico.
} 
políticos sobre uma questão, são utilizadas pelos atores para controlar uma política, amparados em estruturas institucionais. Assim, as ideias são centrais ao modelo, porém são compreendidas em conjunto com a dimensão institucional, elemento menos presente nas análises de John Kingdon. O modelo das coalizões de defesa (SABATIER e JENKINS-SMITH, 1993) sustenta outra interpretação sobre as ideias. Para o modelo, ideias são sistemas de crenças que representam "teorias" sobre como o mundo funciona, ou seja, visões de mundo compartilhadas entre atores. Nesse sentido, ideias que orientam os debates sobre as políticas, elementos menos visíveis aos participantes, como crenças presentes nos esquemas conceituais dos formuladores e da sociedade (ideias como "paradigmas" e "sentimentos públicos", na tipologia de Campbell, 1998) integram o modelo das coalizões de defesa. Por outro lado, a dimensão mais visível das ideias (ideias como "programas" e "enquadramento", como afirma Campbell) também integra o quadro explicativo do modelo. Além disso, as ideias são também relacionadas à ação, uma vez que esses atores buscarão, em coalizões, influenciar as questões que devem receber maior atenção, as relações causais que devem ser examinadas e as instituições governamentais mais favoráveis aos pontos de vista da coalizão (SABATIER e JENKINS-SMITH, 1993, p. 41). Um sistema de crenças envolve "a set of basic values, causal assumptions, and problem perceptions" (SABATIER e JENKINS-SMITH, 1993, p. 25).

Neste contexto em que a argumentação e a defesa de ideias são centrais, é compreensível a importância que o empreendedor assume nos modelos teóricos recentes, uma vez que gerar ideias e disseminá-las é precisamente uma de suas funções mais básicas. Para a promoção de ideias, podemos identificar quatro atividades com as quais o empreendedor se envolve de forma mais direta: a busca pela definição estratégica dos problemas; a estruturação do debate acerca de uma política, oferecendo alternativas para seu encaminhamento; a procura pelo estabelecimento de contatos com diferentes grupos, o que o faz circular dentro de uma comunidade de políticas e para além de seus limites; e, finalmente, a busca de bases institucionais de apoio para suas ideias.

Definir um problema envolve, em primeiro lugar, a transformação de situações percebidas - dinâmicas sociais geralmente já existentes, mas que não demandam ação governamental - em problemas que capturam a atenção governamental e que ensejam ações concretas, transformação operada por meio de processos simbólicos de representação. Situações percebidas transformam-se em problemas por meio de mecanismos que estabelecem valores e comparações (KINGDON, 2003), e imagens que comunicam, de forma simples e direta, as ideias compartilhadas sobre uma política (BAUMGARTNER e JONES, 1993). "Problems are not simply the conditions or external events themselves: there is also a perceptual, interpretative element." (KINGDON, 2003, p. 109-110). É precisamente na promoção de uma interpretação específica sobre um problema que o empreendedor atua. Definir um problema em uma política pública não consiste somente na observação da dinâmica social e no estabelecimento de metas e objetivos para uma mudança. Consiste, sobretudo, na interpretação, na elaboração de representações estratégicas sobre uma determinada situação. O mundo político é socialmente construído, e cada entendimento sobre uma situação é, na realidade, um ponto de vista possível entre diversos outros. Estas interpretações são elaboradas de forma estratégica pelo empreendedor de maneira que o ponto de vista selecionado facilite a mobilização de apoio para um determinado conjunto de ideias, favorecendo um curso de ação desejado. A representação de problemas é essencial tanto no modelo de Kingdon quanto no de Baumgartner e Jones, sendo que ambos destacam esta ação como sendo uma das principais funções do empreendedor. Cabe ressaltar que o empreendedor não "cria" problemas, mas ajuda a "destacar" aspectos de uma determinada questão operando a transformação de situações sociais percebidas em problemas que demandam atuação governamental. Desta forma, consegue atrair a atenção governamental para uma questão e também apontar para algumas respostas políticas consideradas adequadas para tal representação do problema.

Em segundo lugar, outra dimensão importante da atuação do empreendedor concentra-se na estruturação do debate a respeito das mudanças a serem introduzidas numa política, ou seja, a elaboração e circulação de ideias a respeito das alternativas a serem desenvolvidas. Tão importante quanto representar estrategicamente um problema é apresentar formas efetivas de lidar com ele. Algumas características como viabilidade técnica, congruência com os valores da comunidade, aceitação pública e limitações orçamentárias são apontados por Kingdon (2003) como fundamentais para que uma solução seja seriamente considerada, eventualmente selecionada. Baumgartner e Jones (1993) também mostram como a habilidade na construção da imagem de uma política é importante não apenas para mobilizar a atenção e apoio a determinadas proposições. Para eles, quase todas as questões podem ser representadas de forma a assumirem características de legitimidade quase incontestável (valence issues), de forma que a defesa do ponto de vista contrário se torna uma tarefa extremamente difícil, senão impossível. Assim, os empreendedores são geralmente habilidosos não apenas na construção da argumentação sobre as alternativas desejáveis, como também em dificultar a aceitação de alternativas concorrentes. 
A terceira atividade do empreendedor relaciona-se à apresentação de suas ideias para outros indivíduos e grupos, por meio do estabelecimento de contato com diferentes audiências. Esta é uma tarefa importante para o empreendedor, considerando que as comunidades de políticas e os subsistemas são geralmente compreendidos como sendo refratários a mudanças em seu sistema de crenças. No processo de apresentação das ideias descrito por Kingdon, o empreendedor coloca as propostas em teste junto a diferentes grupos, fazendo um trabalho preliminar de observação das reações, como se estivesse experimentando um "balão de ensaio", como afirma o próprio autor. É importante lembrar que esta experimentação é dirigida não apenas às comunidades ligadas a uma política, mas também ao público em geral. Baumgartner e Jones também mostram como os empreendedores atuam na mobilização da atenção de grupos previamente apáticos a uma questão, buscando em diferentes arenas institucionais o apoio para uma ideia de forma a alterar o equilíbrio de uma política existente e possibilitar a mudança. Nos dois casos, destaca-se a importância da interação do empreendedor junto a grupos e instituições em busca da atenção e do apoio desses grupos às ideias defendidas por ele, de forma a ampliar as chances de aceitação de uma determinada representação de problema e de um conjunto de ações propostas. Desta forma, o empreendedor empenha-se no desenvolvimento de estratégias para a apresentação de suas ideias para diferentes audiências, dentro e ao redor do governo, além de buscar as arenas mais favoráveis às suas ideias. Neste processo, embora o objetivo primário do empreendedor seja de convencimento a respeito de suas ideias, ele também busca entender como esses grupos compreendem as questões, aprendendo com as comunidades as formas mais adequadas de retratar uma questão e definir um problema. Os empreendedores buscam, adicionalmente, aumentar sua visibilidade nesses círculos, o que pode ser um ingrediente importante para alavancar sua legitimidade como propositor de mudanças numa política.

Por fim, os empreendedores procuram estabelecer bases institucionais de apoio para suas ideias. Como mostra o modelo do equilíbrio pontuado, a mudança numa política se processa não apenas baseada nas ideias a respeito de problemas e soluções e em sua defesa junto às comunidades de políticas e demais atores. Além de atuarem no plano das ideias, os empreendedores estão atentos aos arranjos institucionais que podem tanto restringir quanto incentivar as decisões relativas à política em questão. O modelo pressupõe uma relação bastante forte entre instituições e ideias: instituições tendem a favorecer algumas ideias mais do que outras. Um arranjo institucional baseia-se em entendimentos sobre questões relevantes de uma política e pode permanecer desta maneira por um longo período, como no caso da constituição dos monopólios de políticas. Assim, muitas vezes os empreendedores buscarão alterar as estruturas institucionais para favorecer determinadas ideias, rompendo com o equilíbrio no sistema político e favorecendo a mudança. Alternativamente, procurarão localizar as arenas institucionais em que podem obter maiores chances de sucesso para suas ideias.

Na promoção dessas atividades, as características apontadas por Kingdon como essenciais ao empreendedor tornam-se fundamentais: gozar de legitimidade frente às audiências, manter conexões políticas e habilidade de negociação, além de ter persistência na defesa das ideias. Outro aspecto importante é que, além dessas habilidades importantes para a defesa das ideias relacionadas a uma política, o empreendedor por vezes exerce a atividade de intermediação dessas ideias (policy brokerage). Empreendedores defendem suas propostas para diferentes audiências e também atuam como intermediários, negociando com os demais grupos e procurando arenas institucionais mais convenientes. Estas são atividades distintas e críticas para o sucesso do empreendedor. Assim, o empreendedor atua não apenas como defensor de ideias, podendo também assumir o papel de negociador. Sobre essas duas ações do empreendedor, Kingdon afirma: "Sometimes, the two activities are combined in a single person; at other times, entrepreneurs specialize, as in the instance of one pushing from an extreme position and another negotiating the compromises" (KINGDON, 2003, p. 183.) Para o autor, empreendedores desempenham o papel de policy brokers, mas o contrário não é verdadeiro (precisamente como verificamos na análise do papel reservado aos policy brokers no modelo das coalizões de defesa).

\section{OS EMPREENDEDORES E AS MUDANÇAS NAS POLÍTICAS PÚBLICAS}

A atuação no sentido da defesa das ideias consiste em um dos papéis mais importantes desempenhados pelos empreendedores nos modelos teóricos de políticas públicas. Há, ainda, outra dimensão fundamental na atuação desses atores: sua atuação como agentes facilitadores na introdução de mudanças nas políticas públicas.

Tanto a análise de Kingdon quanto a de Baumgartner e Jones lidam com a questão das mudanças em políticas públicas. Ambos concordam que há um forte componente incremental no processo decisório, que resulta em mudanças lentas e graduais. No entanto, ambos os modelos mostram também que, muitas vezes, uma mudança se apresenta de forma súbita, rompendo 
com a lógica incremental. Reafirmando a diferenciação entre agendas e alternativas ${ }^{5}$, Kingdon mostra que a geração de alternativas obedece aos parâmetros do incrementalismo, o que não acontece na formação da agenda. Para ele, "To return to our distinction between the agenda and the alternatives, agenda change appears quite discontinuous and nonincremental. But incrementalism might still characterize the generation of alternatives. As policy makers consider the alternatives from which they will choose, the repair to ideas and approaches with which they are already familiar" (KINGDON, 2003, p. 82).

Desta forma, Kingdon conclui que o conteúdo das ideias é mais estável do que seu aparecimento na agenda. Baumgartner e Jones mostram que da mesma forma como podemos observar o mecanismo da mudança incremental, há momentos em que mudanças bruscas ocorrem e, para estas, a ciência política não propõe explicações adequadas, sendo exatamente essa a lacuna que o modelo proposto pelos autores visa suprir:

Punctuated-equilibrium theory seeks to explain a simple observation: Political processes are often driven by a logic of stability and incrementalism, but occasionally they also produce large-scale departures from the past. (...) The observation, then, is that both stability and change are important elements of the policy process, Most policy models have been design to explain, or at least have been more successful at explaining, either the stability or the change. The punctuated-equilibrium theory encompasses both. (BAUMGARTNER, JONES e TRUE, 1999, p. 97).

O empreendedor de Kingdon e o de Baumgartner e Jones estão no centro das explicações sobre as rápidas mudanças, sendo sua ação essencial para a compreensão deste tipo de alteração. Para o modelo de múltiplos fluxos, o empreendedor é central para a mudança na agenda ao se configurar como o elemento chave para a conexão dos três fluxos (coupling) durante os breves momentos de abertura das "janelas de oportunidade". O empreendedor percebe as oportunidades para a mudança e inicia o processo de aproximação entre problemas e soluções, considerando as oportunidades que emergem do contexto político. No modelo do equilíbrio pontuado, a atividade do empreendedor está relacionada à criação e manutenção de um monopólio de políticas, por meio de duas ações específicas: definindo uma imagem, ou seja, ideias e entendimentos sobre uma política, e uma estrutura institucional que favoreça tal imagem. Considerando que o modelo baseia as explicações sobre mudança no funcionamento dos monopólios, podemos considerar que o empreendedor tem papel central na mudança de políticas - e também em sua estabilidade. O empreendedor, no modelo do equilíbrio pontuado, vincula-se à mudança de políticas públicas por meio da manipulação das ideias (a respeito de problemas e soluções) e das instituições. No modelo de múltiplos fluxos, manipula preferências dos formuladores de política, por meio da defesa de ideias a respeito de problemas e soluções. Em ambos os casos, o "senso de oportunidade" é fundamental ao empreendedor.

Por outro lado, não se trata apenas da percepção do momento oportuno: sem uma imagem construída, o empreendedor de Baumgartner e Jones é incapaz de estabelecer seu monopólio de políticas (ou limitado em sua busca pela ruptura de um monopólio existente); sem uma definição clara sobre os problemas, o empreendedor de Kingdon pode perder o momento de oportunidade de mudança sem conseguir provocar alterações em uma política. O empreendedor é o indivíduo que consegue perceber os fatores externos - as oportunidades presentes nas esferas políticas, sociais, econômicas - e conciliá-los ao seu trabalho árduo de geração, disseminação e defesa de ideias. As inovações, para o empreendedor de políticas púbicas, estão diretamente relacionadas às mudanças nas políticas (MINTROM e NORMAN, 2009) e à difusão de novas ideias (MINTROM, 1997). Com relação à atividade inovativa, os empreendedores desempenham três funções específicas, de acordo com Mintrom e Vergari (1996). Em primeiro lugar, os empreendedores descobrem "necessidades não satisfeitas" e sugerem formas de satisfazê-las, atividade para a qual necessitam estar atentos às oportunidades. A segunda função envolve os riscos (concernentes a sua reputação pessoal, recursos financeiros e mesmo emocionais) nos quais o empreendedor envolve-se na busca de ações que têm consequências incertas. E, finalmente, os empreendedores coordenam redes envolvendo grupos de pessoas e organizações, necessários para garantir a realização das mudanças. Sendo assim, os empreendedores não são indivíduos atomizados, pelo contrário, estão (e necessitam estar) inseridos em redes sociais. Tais características estão presentes tanto no empreendedor de Kingdon, quanto no de Baumgartner e Jones.

\footnotetext{
${ }^{5}$ Kingdon considera as políticas públicas como um conjunto formado por quatro processos que compreendem: o estabelecimento de uma agenda de políticas; a especificação de alternativas a partir das quais as escolhas sobre uma política vão ser realizadas; a escolha dominante entre o conjunto de alternativas disponíveis e, finalmente, a implementação da decisão. Em seu modelo, o autor se preocupa especificamente com os dois primeiros processos, denominados estágios pré-decisórios: a formação da agenda (agenda-setting) e a especificação de alternativas (policy formulation).
} 
Na tabela apresentada a seguir, procuramos sintetizar a forma como os modelos lidam com a ação do empreendedor de políticas públicas, em suas duas dimensões principais: defesa de ideias e mudança nas políticas.

Quadro 1

O empreendedor nos três modelos de políticas públicas

\begin{tabular}{|c|c|c|c|}
\hline & Múltiplos Fluxos & Equilíbrio Pontuado & Coalizões de Defesa \\
\hline Conceito de ideias & $\begin{array}{c}\text { Problemas } \\
\text { (enquadramento; relações } \\
\text { causais; indicadores; } \\
\text { eventos...). } \\
\text { Ideias como "enquadramento" } \\
\text { Soluções } \\
\text { (viabilidade técnica; aceitação; } \\
\text { custos). } \\
\text { Ideias como "programas" }\end{array}$ & $\begin{array}{c}\text { Problemas } \\
\text { (enquadramento (tone); } \\
\text { relações causais; indicadores; } \\
\text { eventos,...). } \\
\text { Ideias como "enquadramento" } \\
\text { Soluções } \\
\text { (viabilidade técnica; aceitação; } \\
\text { custos) } \\
\text { Ideias como "programas" } \\
\text { Estrutura institucional } \\
\text { associada às ideias } \\
\text { (monopólio) }\end{array}$ & $\begin{array}{l}\text { Sistemas de crenças } \\
\text { (valores básicos; relações } \\
\text { causais; percepção de } \\
\text { problemas) } \\
\text { Ideias como "programas", } \\
\text { "enquadramento"; } \\
\text { "paradigmas" e } \\
\text { "sentimentos públicos" }\end{array}$ \\
\hline $\begin{array}{l}\text { Atuação do } \\
\text { empreendedor: defesa } \\
\text { de ideias }\end{array}$ & $\begin{array}{l}\text { Definição estratégica dos } \\
\text { problemas; } \\
\text { Estruturação dos debates } \\
\text { relativo às soluções; } \\
\text { Apresentação e defesa de } \\
\text { ideias sobre problemas e } \\
\text { soluções. } \\
\text { Ideias como "paradigmas" e } \\
\text { como "sentimentos públicos" }\end{array}$ & $\begin{array}{l}\text { Definição estratégica dos } \\
\text { problemas; } \\
\text { Estruturação dos debates } \\
\text { relativo às soluções; } \\
\text { Apresentação e defesa de } \\
\text { ideias sobre problemas e } \\
\text { soluções. } \\
\text { Estabelecimento de bases } \\
\text { institucionais de apoio às } \\
\text { ideias }\end{array}$ & $\begin{array}{l}\text { Empreendedor não é } \\
\text { figura central: policy broker } \\
\text { (mediador) pode ou não } \\
\text { defender ideias relativas a } \\
\text { uma política. }\end{array}$ \\
\hline $\begin{array}{c}\text { Atuação do } \\
\text { empreendedor: } \\
\text { mudanças nas políticas }\end{array}$ & $\begin{array}{l}\text { Conexão entre problemas, } \\
\text { soluções e contexto político } \\
\text { (coupling) }\end{array}$ & $\begin{array}{l}\text { Criação e manutenção dos } \\
\text { monopólios de políticas: } \\
\text { definição de imagens e de } \\
\text { estruturas institucionais }\end{array}$ & $\begin{array}{c}\text { Policy broker poderia atuar } \\
\text { como empreendedor na } \\
\text { formação e manutenção } \\
\text { de coalizões (Mintrom e } \\
\text { Vergari, 1996) }\end{array}$ \\
\hline
\end{tabular}

Fonte: Elaborado pela autora. 


\section{CONSIDERAÇÕES FINAIS}

O estudo procurou mostrar que são dois os principais papéis do empreendedor: defender ideias e facilitar a introdução de mudanças em processos de políticas públicas, em especial em seu momento de formação. As abordagens teóricas examinadas neste estudo exploram de forma distinta a ação dos empreendedores, além de lidarem de maneira diferente com o contexto no qual eles atuam, ou seja, com os arranjos institucionais existentes. O empreendedor é o indivíduo (ou grupo de indivíduos) que age combinando interesses e ideias, uma vez que esse ator mobiliza-se em função de benefícios materiais e também da promoção de valores relacionados a uma política (KINGDON, 2003). Essas duas dimensões da atuação do empreendedor manifestam-se em um conjunto de ações voltadas à manipulação do processo decisório, uma vez que o empreendedor buscará controlar tanto as regras formais e a dimensão institucional da tomada de decisão quanto os argumentos desenvolvidos em torno de uma questão (BAUMGARTNER e JONES, 1993). A análise da atuação do empreendedor poderia ampliar as explicações sobre a dinâmica das coalizões, sua formação e mudança, ampliando a capacidade explicativa do modelo de coalizões de defesa (MINTROM e VERGARI, 1996).

A investigação sobre a atuação de empreendedores de políticas públicas pode contribuir significativamente para o desenvolvimento teórico no campo da Administração Pública. Ao focalizar a atenção no papel do empreendedor, a pesquisa em administração pública pode incorporar a dimensão das ideias, perspectiva em desenvolvimento no campo dos estudos em políticas públicas desde os anos 1990 e que ainda não tem estimulado suficientemente os debates teóricos e metodológicos na área de Administração Pública. Além disso, considerando que as abordagens teóricas aqui apresentadas dialogam em grande parte com a fase de formulação de políticas (tanto a formação da agenda como a seleção de alternativas e soluções), a análise da atuação empreendedora pode auxiliar na investigação de elementos pré-decisórios, contribuindo para a compreensão de processos anteriores à tomada de decisão em organizações públicas, podendo estimular novos entendimentos sobre o próprio processo decisório, seus resultados e impactos na implementação de políticas públicas. Uma terceira contribuição ao campo da Administração Pública reside em novas possibilidades para a análise de processos de mudança. Considerando o papel central do empreendedor em processos de transformações rápidas, a incorporação desse conceito pode auxiliar nas explicações sobre a condução de mudanças organizacionais na administração pública. A análise da atuação do ex-Ministro Bresser Pereira no processo de reforma na administração pública brasileira pode exemplificar a atuação empreendedora e os novos sentidos que essa categoria analítica permite conferir aos estudos sobre mudanças na gestão pública. Bresser Pereira assumiu claramente o papel de empreendedor, da maneira como as abordagens teóricas aqui apresentadas definem esse ator: investindo recursos - tempo, energia, prestígio, reputação - em função de uma ideia (CAPELLA, 2004). O então Ministro empenhou-se não apenas em difundir as ideias contidas no Plano Diretor (BRASIL, 1995) mas também em defendê-las para diferentes audiências (acadêmicos, jornalistas, servidores públicos, entre outros) utilizando estratégias de comunicação distintas, assumindo o papel, em suas próprias palavras, de "advogado nacional da reforma" (BRESSER PEREIRA, 1999, p. 16). Além disso, atuou decisivamente tanto na definição do problema (a argumentação a respeito da crise do modelo burocrático de administração pública) quanto na apresentação de soluções (a reforma gerencial norteada pelos projetos definidos no Plano Diretor), conectando as duas dimensões do ponto de vista ideacional. É importante mencionar também seu papel como articulador político da reforma junto às demais instâncias governamentais para além do MARE (Ministério da Administração Federal e Reforma do Estado, sob sua responsabilidade). Uma dimensão importante da análise desse processo de mudança na administração pública brasileira reside, precisamente, na atuação do ex-Ministro como empreendedor da reforma gerencial. Analisar a atuação do empreendedor pode, portanto, lançar novas luzes sobre a forma como esses atores apresentam e defendem novas ideias relativas a uma política, como desafiam os obstáculos institucionais e intelectuais que se contrapõem a essas ideias, como desenvolvem a lógica e o conteúdo argumentativos aliados ao desempenho e à articulação junto à audiência, ou seja, como realizam a análise técnica e a articulação política, elementos centrais da argumentação e defesa de uma política (FISCHER e FORESTER, 1993). Diversas análises empíricas têm confrontado as explicações dos modelos teóricos aqui analisados sobre o empreendedor com o estudo de casos particulares (MINTROM, 1997). Além disso, a atuação dos empreendedores tem sido investigada não apenas na literatura mais específica sobre formulação de políticas mas também nos estudos sobre inovação e difusão de políticas (BERRY e BERRY, 1999). No entanto, algumas observações devem ser feitas a respeito do papel de protagonismo assumido pelo empreendedor nesses estudos. 
Em primeiro lugar, é preciso evitar uma visão causal e voluntarista a respeito dos empreendedores. Nos estudos conduzidos por John Kingdon, em nenhum momento um indivíduo foi identificado como sendo unicamente responsável pela elevação de uma questão à agenda. Aliás, as ações do empreendedor de Kingdon são restringidas pelo fluxo político, dimensão que escapa ao controle do indivíduo. Afinal, mesmo um empreendedor que consiga êxito na representação de problemas, na apresentação de alternativas socialmente aceitáveis e tecnicamente viáveis, e mesmo que esse mesmo indivíduo seja habilidoso na junção das duas dimensões, de nada adiantará seu esforço enquanto a opinião pública não se mostrar favorável à ideia, ou enquanto o sistema político não se mostrar favorável à mudança. Nas análises de Baumgartner e Jones, há diversos elementos que interagem para a produção das explicações sobre as mudanças numa política. A mudança não é produto exclusivamente da ação do empreendedor, mas certamente a atuação dos empreendedores é central principalmente nas abordagens que analisam as mudanças considerando o papel das ideias e que procuram analisar períodos de rápidas e profundas alterações. Os empreendedores não "podem tudo", mas sua atuação é visível, como diz Kingdon, enquanto "personagens centrais do drama" (KINGDON, 2003, p. 180). Nas palavras do próprio autor, "Our treatment of policy entrepreneur in this book argues that much of the process is governed by large events and structures not under any individual's control. But entrepreneurs take advantage of those events and work within those structures, which is the way we include the importance of both individuals and structures". (KINGDON, 2003, p. 225).

Outro ponto importante a salientar é que nem todos os empreendedores são hábeis. Muitas vezes, ao descrever as ações desses atores, os modelos parecem atribuir qualidades quase "sobre-humanas" aos empreendedores. Muitos deles podem aguardar por anos uma onda que nunca virá, para retomar a metáfora de Kingdon. Ou podem simplesmente perder o equilíbrio no exato momento em que ela poderia levá-los à praia. Empreendedores podem simplesmente perder a oportunidade para a mudança, podem defender uma proposta durante muito tempo sem sucesso algum.

Os empreendedores também não devem ser compreendidos como indivíduos atomizados, "soltos" dentro de um universo de políticas. Empreendedores não são indivíduos isolados que se destacam por suas qualidades ou características pessoais. Fundamental para a compreensão da atuação do empreendedor é considerar que ele está imerso em redes sociais. É bem verdade que a posição do empreendedor na estrutura governamental é menos importante do que as ações que desenvolve: um empreendedor pode estar em qualquer ponto de uma rede de atores que se articula em torno de uma política, dentro ou fora do governo. Mas não há como considerar a atuação de um empreendedor desvinculado de redes sociais, de comunidades diretamente envolvidas com a questão relacionada à política e da própria rede em que esse empreendedor circula.

Uma observação, feita pelo próprio Kingdon a respeito dos empreendedores não pode ser esquecida. Sua teoria sobre a formação da agenda, baseada no modelo organizacional da "lata de lixo" (garbage can), pressupõe uma visão bastante peculiar sobre o processo decisório e sobre a própria dinâmica organizacional. No modelo da lata do lixo (MARCH, OLSEN e COHEN, 1972), as organizações são consideradas "anarquias organizadas", operando em condições de grande incerteza e ambiguidade, nas quais a participação no processo decisório se desenvolve de maneira fluída, instável e com grande rotatividade; as preferências dos participantes são inconsistentes e mal definidas; e os processos e procedimentos organizacionais são pouco claros e em geral mal compreendidos por parte dos participantes. Baseada nestes pressupostos, a visão de empreendedor sugerida por Kingdon, seria viável. No entanto, se as metas e objetivos de uma política são, por exemplo, definidos de maneira precisa, não há espaço para o empreendedor procurar oportunidades. Ideias inovativas se desenvolvem em sistemas imprecisos e incertos, tal como descreve o modelo da lata do lixo, favorecendo a criatividade e a própria mudança.

Cabe destacar, ainda, que o foco na ação do empreendedor revela que a ação individual é uma dimensão importante da produção de políticas públicas, principalmente considerando momentos de rápidas mudanças. Embora não sejam "super-heróis" (titanic individuals, como diz Kingdon), em diversas ocasiões é possível identificar um indivíduo em particular que se aproveita de um momento para tentar mudar uma política, juntamente com seu "senso de oportunidade". Suas habilidades na defesa de ideias, na negociação com diferentes grupos, na busca de bases institucionais de apoio para suas propostas são essenciais para compreender as mudanças. A mudança numa política se processa por motivos alheios ao alcance do indivíduo, mas é ele quem aproveita as oportunidades. Assim, a ênfase no papel do empreendedor pode ser uma forma de contribuir para o aprofundamento na compreensão das relações entre ação individual e estrutura institucional no processo de produção de políticas públicas. 
Por fim, é preciso considerar que os modelos aqui analisados consistem em "lentes teóricas" (SABATIER, 1999) projetadas para o desenvolvimento de explicações em um contexto histórico, político-administrativo e social distinto da realidade brasileira. A realização de estudos de caso pode afirmar os limites e possibilidades desse referencial teórico em tratar adequadamente as especificidades e as características da produção de políticas no Brasil. Por outro lado, é preciso considerar que um dos maiores desafios da pesquisa em administração pública e políticas públicas no país atualmente reside nos aspectos teóricos e metodológicos da produção acadêmica (FARAH, 2013). Os modelos analisados já são bastante conhecidos na literatura internacional há algumas décadas e, embora não sejam mais "ignorados" pela pesquisa em políticas públicas no país, como apontado por Faria há pouco mais de uma década (FARIA, 2003), ainda são pouco utilizados (CAPELLA, SOARES e BRASIL, 2014). Assim, ainda há muito a ser feito do ponto de vista da aplicação desses modelos e seus conceitos no Brasil, especialmente considerando a multiplicidade de estudos setoriais passíveis de análise nesse período de forte expansão dos estudos sobre políticas públicas. 


\section{REFERÊNCIAS}

BATTILANA, J.; LECA, B.; BOXENBAUM, E. How Actors Change Institutions: Towards a Theory of Institutional Entrepreneurship. The Academy of Management Annals, v. 3, n. 1, p. 65-107, 2009.

BAUMGARTNER, F. R.; JONES, B. D. Agendas and Instability in American Politics. Chicago: University of Chicago Press, 1993.

BAUMgartneR, F. R; JONES, B. D. The Politics of Attention: How government priorizes problems. Chicago: University of Chicago Press, 2005.

BERRY, F. S.; BERRY, W. D. Innovation and Diffusion Models in Policy Research. In: SABATIER, P. A. Theories of the Policy Process. Oxford: Westview Press, 1999.

BÉLAND, D.; COX, R. H. Ideas and Politics in Social Science Research. New York: Oxford University Press, 2011.

BRASIL. Plano Diretor da Reforma do Aparelho do Estado. Brasília: Presidência da República, 1995. 83 p.

BRESSER PEREIRA, L. C. Reflexões sobre a Reforma Gerencial Brasileira de 1995. Revista do Serviço Público, v. 50, n. 4, p. 05-30, jan./mar. 1999.

CAMPBELL J. L. Institution analysis and the role of ideas in political economy. Theory and society, v. 27, n. 3, p. 377-409, 1998.

CAMPBELL, J. L. Ideas, politics and public policy. Annual Review of Sociology, v. 28, p. 21-38, 2002.

CAPELLA, A. C. N. O Processo de Agenda-Setting na Reforma da Administração Pública (1995-2002). Tese (Doutorado). Programa de Pós-Graduação em Ciências Sociais, Universidade Federal de São Carlos, 2004.

CAPELLA, A. C. N.; SOARES, A. G.; BRASIL, F. G. Pesquisa em Políticas Públicas no Brasil: Um mapeamento da aplicação de modelos internacionais recentes na literatura nacional. In: IX Encontro da ABCP. Anais eletrônicos. Associação Brasileira de Ciência Política, 2014. Disponível em < http://www.encontroabcp2014.cienciapolitica.org. br/resources/anais/14/1403738847_ARQUIVO_ABCP_final.pdf>. Acessado em: 20 out. 2014.

COHEN, M. D.; MARCH, J. G.; OLSEN, J. P. A Garbage Can Model of Organizational Choice. Administrative Science Quarterly, v. 17, p. 1-25, 1972.

DiMAGGIO, P. Interest and agency in institutional theory". In: Zucker, L. (Ed.). Institutional patterns and culture. Cambridge, MA: Ballinger Publishing Company, 1988.

DUNN, W. N. Public Policy Analysis. Englewood Cliffs, New Jersey: Prentice-Hall, 1994.

FARAH, M. F. S. A contribuição da Administração Pública para a constituição do campo de estudos de políticas públicas. In: MARQUES, E.; FARIA, C. A. P. A Política Pública como Campo Multidisciplinar. São Paulo/Rio de Janeiro: Unesp/Fiocruz, 2013.

FARIA, C. A. P. Ideias, Conhecimento e Políticas Públicas: Um inventário sucinto das principais vertentes analíticas recentes. Revista Brasileira de Ciências Sociais, v. 18, n. 51, p. 21-29, fevereiro 2003.
FISHER, F.; FORESTER, J. The Argumentative Turn in Policy Analysis and Planning. London, Duke University Press, 1993.

HARDIN, R. Collective Action. Baltimore. The John Hopkins Press, 1982.

JOHN, P. Ideas and interests; agendas and implementation: an evolutionary explanation of policy change in British local government finance. British Journal of Politics and International Relations, v. 1, n. 1, p. 39-62, 1999.

KINGDON, J. Agendas, Alternatives, and Public Policies. 3. Ed. New York: Harper Collins, [1984] 2003.

MAJONE, G. Evidence, Argument, \& Persuasion in the Policy Process. London: Yale University Press, 1989.

MARCH, J. G.; OLSEN, J. P.; COHEN, M. D. A Garbage Can Model of Organizational Choice. Administrative Science Quarterly, v. 17, p. 1-25, 1972.

MARTES, A. C. B. Weber e Schumpeter: A ação econômica do empreendedor. Revista de Economia Política, v. 30, n. 2 (118), p. 254-270, abr./jun. 2010.

MINTROM, M. Policy Entrepreneurs and the Diffusion of Innovation. American Journal of Political Science, v. 41, n. 3, p. 738-770, 1997.

MINTROM, M.; NORMAN, P. Policy Entrepreneurship and Policy Change. Policy Studies Journal, v. 37, n. 4, p. 649-667, 2009.

MINTROM, M.; VERGARI, S. Advocacy Coalitions, Policy Entrepreneurs, and Policy Change. Policy Studies Journal, v. 24, n. 3, p. 420-434, 1996.

OLSON, M. Apêndice. In: OLSON, M. (Ed.). A Lógica da Ação Coletiva: os benefícios públicos e uma teoria dos grupos sociais. São Paulo: USP, [1965] 1999.

RIDDE, V. Policy implementation in an african state: an extension of Kingdon's multiple-streams approach. Public Administration, v. 87, n. 4, p. 938-954, 2009.

RIKER, William. H. The Art of Political Manipulation. New Haven: Yale University Press, 1986

SABATIER, P. (Ed.). Theories of the Policy Process. Oxford: Westview Press, 1999.

SABATIER, P. A. The Advocacy Coalition Framework: An Assessment. In: Sabatier, P. (Ed.). Theories of the Policy Process. Oxford, Westview Press, 1999.

SABATIER, P. A.; JENKINS-SMITH, H. C. Policy Change and Learning: An Advocacy Coalition Approach. Oxford: Westview Press, 1993.

SCHLAGER, E. A Comparison of Frameworks, Theories, and Models of Policy Process. In: Sabatier, P. (Ed.). Theories of the Policy Process. Oxford, Westview Press, 1999.

SCHNEIDER, M.; TESKE, P.; MINTROM, M. Public Entrepreneurs. New Jersey: Princeton University Press, 1995.

SCHUMPETER, J. A. Teoria do Desenvolvimento Econômico. São Paulo: Abril Cultural, [1912], 1982. 
SCHUMPETER, J. A. Capitalismo, Socialismo e Democracia. Rio de Janeiro: Zahar, [1942], 1984.

SHEPSLE, K. A. Rational Choice Institutionalism. In: RHODES, R. A. W.; BINDER, S. A.; ROCKMAN, B. A. Rockman. The Oxford Handbook of Political Institutions. Oxford: Oxford University Press, 2008.

STONE, Deborah. Policy Paradox: The Art of Political Decision Making. Nova York: Norton \& Company, [1997], 2002.

TRUE, J. J.; BAUMGARTNER, F. R; JONES, B. D. Punctuated-Equilibrium Theory: Explaining stability and change in American policymaking. In: Sabatier, Paul A. Theories of the Policy Process. Oxford: Westview Press, 1999.

WAGNER, R. E. "Pressure Groups and Political Entrepreneurs: A review article Papers on Non-Market Decision Making, 1966. 161-170 p.
WEIBLE, C. C.; SABATIER, P. A.; McQUEEN, K. Themes and Variations: taking stock of the advocacy coalition framework. Policy Studies Journal, v. 37, n. 1, p. 121-140, 2009.

YANOW, D. How Does a Policy Mean? Interpreting Policy and Organizational Actions. Washington: George Washington University Press, 1996.

ZAHARIADIS, N. Ambiguity, Times and Multiple Streams. In: SABATIER, P. A. (Ed.). Theories of the Policy Process: Theoretical Lenses on Public Policy. Boulder, CO: estview Press, 1999. 73-93 p.

ZAHARIADIS, N. The multiple streams framework: structure, limitations, prospects. In: SABATIER, P. A. (Ed.). Theories of the Policy Process: Theoretical Lenses on Public Policy. 2 ed. Boulder, CO: Westview Press, 2007. 65-91 p. 